
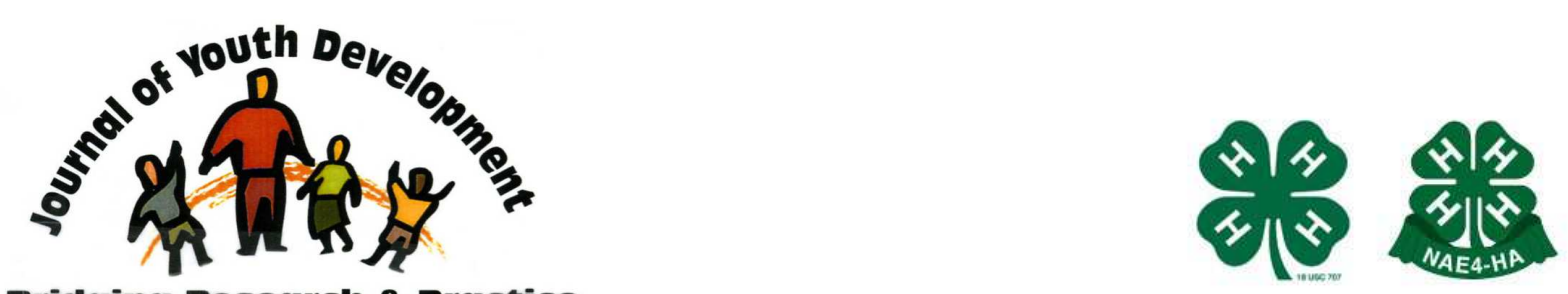

\title{
Summer Programming: What Do Children Say?
}

\author{
Nila Cobb \\ WVU Cabell County Extension \\ Ona, WV \\ Nila.Cobb@mail.wvu.edu \\ Stacey Harper \\ WVUES Energy Express \\ Morgantown, WV \\ SEHarper@mail.wvu.edu \\ Kerri McCormick \\ WVU Kanawha County Extension \\ Dunbar, WV \\ KJMcCormick@mail.wvu.edu \\ Kimary McNeil \\ WVU Nicholas County Extension \\ Summersville, WV \\ Kimary.McNeil@mail.wvu.edu \\ Margaret Miltenberger \\ WVU Mineral County Extension \\ Keyser, WV \\ M.Miltenberger@mail.wvu.edu
}

Ruthellen Phillips

WVUES Energy Express

Morgantown, WV

RHPhillips@mail.wvu.edu

Ruth Schneider

Indiana University

Burlington, WV

rmoffa@care2.com

Gina Taylor

West Virginia State Extension

Institute, WV

taylorgi@wvstateu.edu

Shirley Wilkins

WVU Pocahontas County Extension

Marlinton, WV

Shirley.Wilkins@mail.wvu.edu 


\title{
JOURNAL OF YOUTH DEVELOPMENT bridging research and practice
}

\section{Summer Programming: What Do Children Say?}

\author{
Nila Cobb, Stacey Harper, Kerri McCormick, Kimary McNeil, and Margaret Miltenberger \\ West Virginia University
}

Ruthellen Phillips, Gina Taylor, and Shirley Wilkins

West Virginia University Extension

Ruth Schneider

Indiana University

\begin{abstract}
Studies document that low-income children lose academic skills over the summer. Six years of reading achievement data collected by Energy Express, a nationally recognized summer reading and nutrition program in West Virginia, has established the efficacy of the intervention. The purpose of this study was to examine characteristics of a voluntary summer program that foster participation. Interview data indicates that children attend because they perceive the program as fun; large creative art (for example, full-body portraits, appliance box castles, wall murals) seems particularly important. Energy Express gives children both the fun they want and the enrichment they need in the summer.
\end{abstract}

\section{Introduction}

Standardized tests document what teachers have long known - when students are not involved in learning activities during the summer, they experience learning losses. A review of 30 studies by Cooper, Nye, Charlton, Lindsay and Greathouse (1996) indicated that: achievement test scores decline during the summer; low-income children experience greater losses than their middle income peers; and low-income children experience an average summer learning loss in reading achievement of over two months. Alexander and Entwisle (1996) contend that the cumulative effect of these differences in summer learning losses is a primary cause of the achievement gap between low and middle income children. The erosion of skills makes summer time costly for low-income children and widens the gap between poor and more advantaged children. 
Children who attend summer school programs score higher on achievement tests when they return to school at the end of the summer. A meta-analysis of 93 evaluations of summer school programs across the country demonstrated that participation in summer school has a clear positive impact on the knowledge and skills of low-income and middle-income students. Cooper, Charlton, Valentine and Muhlenbruch (2000) found the average student who attends summer school scores $5 \%$ to $10 \%$ higher on achievement tests than similar students who do not attend.

There are indications that "out-of-school-time" enrichment activities also lessen the achievement gap. A group of researchers analyzed 56 studies which looked at the impact of out-of-school-time strategies on at-risk students, (Lauer, Akiba, Wilkerson, Apthorp, Snow \& Marti-Glenn, 2003). They concluded that out-of-school-time strategies, whether after school or during the summer, can have positive effects on the achievement of these students.

While summer learning programs have the ability to reverse the typical "summer slide" which widens the achievement gap between low- and middle-income children, there are challenges for voluntary summer programs: meeting parents' expectations for the children's summer participation, enrolling children from targeted families and maintaining consistent attendance during the summer months.

\section{Program Description}

In light of these challenges, what are the characteristics of summer programs that foster the participation of targeted children? This study of children who participated in Energy Express, a voluntary summer reading program in West Virginia, begins to answer that question.

Energy Express is a six-week summer program designed to promote the school success of children living in more than 80 low-income rural communities in West Virginia. The program seeks to maintain the nutritional status and reading achievement of poor children while providing a safe and secure environment. Community agencies and organizations work together to form a collaborative to support an Energy Express site; a public school teacher serves as site coordinator. This community-based approach creates local ownership and helps move the program toward sustainability.

Children entering first through sixth grade attend Energy Express five days a week for three and half-hours each day. College student AmeriCorps Members serve as mentors and work with small groups of eight children to create a print-rich environment. Children stay in their small groups for family-style breakfast and lunch, provided under the auspices of the United States Department of Agriculture's Summer Food Service Program (SFSP), practicing social skills and learning good nutrition. Seventy percent of the children are eligible for free and reduced priced meals. The meals help to maintain growth over the summer and ensure that the children are ready to learn when they return to school in the fall. Statewide, more than 3000 children participate each summer. Daily attendance averages eighty two percent in Energy Express communities.

Unlike formal instruction strategies used during the school year, a literature based language arts curriculum that focuses on reading is used by Energy Express. The program helps children 
create a print-rich, art-rich environment in which there are many opportunities to practice and use reading skills. The AmeriCorps mentors guide the children through enriching experiences to make reading more meaningful in their lives. This less formal curriculum is place-based with weekly themes that build on the children's experiences and their connections to the people and places around them. Writing, art, and drama are integral parts of each day. In addition to read alouds, community volunteers read one-on-one with each child for 15 to 20 minutes each day. Every week each child receives a free take-home book to keep.

The small group size, maintenance of a noncompetitive environment, and vertical age-grouping are carefully considered components of the program model. The ratio of eight children to one college student mentor is intended to create opportunities for children to receive a great deal of individual attention and to connect with the mentor and group members. The noncompetitive environment encourages children to cooperate to achieve group goals, thus creating a safe place where children feel comfortable taking risks. Grouping children vertically, with at least three grades in each small group, helps mask the differences in "grade level appropriate" achievement and promotes cross-age interaction.

For the past eight years, Energy Express has conducted comprehensive evaluations to determine program impact. At the beginning and end of each summer, a stratified random sample of $15 \%$ - $25 \%$ of the program participants completes three subtests of the Woodcock Johnson Tests of Reading Achievement (letter/word identification, reading fluency and passage comprehension which then comprise a broad reading score). The selected children are representative of the overall population of Energy Express. Results have been consistent over the eight years of testing. Using an average of the eight summers, $70 \%$ of the children who attended at least 15 days of the six week program maintained or increased reading achievement with a gain of 3.25 months for the "average" child. Overall increases on pre- and post tests in all three subsets have been significant at the .05 level or above.

Quality relationships with adults make a difference for children. A qualitative study using a sample of parents and teachers concluded that Energy Express provides opportunities for children to develop positive relationships with college students thus enhancing their learning (Miltenberger, Phillips, Pruett \& Triplett, 2002).

Teach Baltimore, an inner-city summer program for low-income kindergarten and first grade children that is also staffed by college student AmeriCorps members, demonstrates similar success. A study found that the program was successful in helping children achieve academically. Participating children were given the CTBS/4 at the beginning and end of each summer and at the end of the third or fourth grade. Marked and sustained improvement in student reading skills was reported (Borman, Rachuba, Hewes, Boulay, \& Kaplan, 2001).

Parents play a role in children's participation in summer activities and have clear notions about their expectations for the summer. Results of a national survey indicated that parents from all income levels want their children to have fun in the summer, regardless of pressures to meet educational standards, high-stakes testing, and "getting ahead." Forty-three percent of parents mentioned having fun as one of the three most important expectations, and more than a quarter named "having fun" as the most important. "In many communities, parents perceive that high-stakes testing programs have increased the emphasis on "drill and kill" to the detriment of learning in fun, creative, and enjoyable ways" (LeMenestral, 2002). 


\section{Research Design}

A qualitative research design was used to collect data by interviewing children who had participated in Energy Express the previous summer. The research protocol was designed to be appropriate for children. The sample of 38 children from eight Energy Express sites was interviewed six to eight months following the summer program. The children were asked:

- "Why did you attend Energy Express this summer?"

- "What did you like about the program?"

- "Do you have friends who should participate in Energy Express?

- "Why should your friends participate in Energy Express?"

Some interviews were conducted one on one, others in small groups of two to three children. The interviews were taped on site and transcribed collectively by one person.

The verbatim transcripts served as the data source for analysis. The qualitative analysis method involved the division of the data into relevant and meaningful groups while maintaining a connection to the whole (Gredler, 1996). Team members reviewed the transcripts and identified the major themes. Once the group reached consensus about the major themes, a coding system was developed and transcripts were coded to further identify patterns emerging across the data. Researchers reached consensus on the validity of the findings based on the data and conducted group analysis to define the results.

The accuracy of the audiotape transcription is determined by the quality of the audio tape, the clarity of a respondent's diction and the transcriber's familiarity with a respondent's accent or speech patterns. Some errors could have occurred in the data transcript. A high degree of accuracy was achieved by the simultaneous review of audiotape and transcripts by the nine member research team which reviewed the data, developed the codes and determined the conclusions.

\section{Major Findings}

The data collected from interviews with children who participated in Energy Express in 2000 yielded findings related to three research questions:

- Why do children attend Energy Express, a voluntary summer program?

- What do children like about the program?

- Why do children think their friends should attend the program?

From the numerous responses, dominant themes emerged to answer each of the questions.

\section{Why Do Children Attend Energy Express?}

Children were asked why they attended Energy Express. While references were made to parents wanting them to attend and not having other summer activities, the most dominant theme that emerged was that children attend because they perceive Energy Express as fun. The following comments were typical of the children's answers. 
"Because I thought it was going to be fun, and it was."

"To have fun because there is usually nothing to do at the house. I just came to have fun."

"It's fun, it's not like school."

"You do activities and you read books. It's fun"

"Because it's more fun than just sitting around all day watching TV."

\section{What Do Children Like About Energy Express?}

Children were asked what they liked about the program. In addition to mentioning their relationships with college student AmeriCorps Members and family-style meals, the most dominant theme centered on the art activities.

Indicative of the children's responses was:

"I liked everything, but especially art."

Some children seemed to enjoy creative art activities as opposed to prescribed projects:

"We drawed our own stuff."

Many of the children's responses described large, creative, expressive art:

"We made a big castle and I got to take a piece home. I used the castle until it was all gone." "We painted ourself. We hanged it up on the wall. We just like got paint ... We imaginary drawed ourselves."

"I put my hair green. Then I put a shirt striped and then put pants on."

While most responses centered on the visual arts, "performing arts" or drama was also mentioned:

"I liked the drama part because we got to do plays and different stories we read and some of the other classes came in and watched us perform and be creative."

\section{Why Do Energy Express Participates Believe Their Friends Should Attend The Program?}

Children were asked if they had friends who should attend Energy Express, and if so, why they should become participants. Most children identified a friend that would benefit from attending. Children's responses indicated that their friends should attend Energy Express because it's fun and because they would enjoy having their friends participate:

"It was a fun place to go."

"So they can have fun too."

"They would have more fun than just sitting around the house."

"She talks about how bored she is in the summer and I think it would be fun for her to come."

Another strong theme indicated that Energy Express would help the friends with their reading:

"I think it would make her a better reader."

"I don't think they read as good as they should. Energy Express builds up more ability to read." 


\section{Discussion}

Children clearly articulate that they attend the Energy Express program because it is fun. They also believe that their friends should attend because "it's a fun place to go." Participation in fun activities at Energy Express was seen as unlike school and an alternative to the boredom experienced by staying at home. This finding coincides with the study by LeMenestral (2002) which found that parents from all income levels want their children to have fun in the summer.

While children talked about the college student mentors and the family-style meals, they seemed to enjoy the expressive art that permeates each Energy Express site. Six to eight months after their participation, children recalled specific art activities. Art is integrated into the Energy Express curriculum as a way to make reading meaningful; it is regarded by children as "fun" and the part of the program they most like. Children identified both visual and dramatic arts as what they like best, but they seemed particularly drawn to large, creative visual art activities such as building castles. Although children did not identify reading as the reason for attending the program, they were very aware that reading is the major focus of Energy Express. They knew of friends who should attend the program and suggested that friends should attend because "Energy Express builds up more ability to read."

\section{Recommendations}

\section{Market programs to parents as fun for their children, as well as educationally} productive. While positive learning outcomes are primary goals of many voluntary summer programs, it is extremely important that children perceive them as fun. The children's enthusiasm for Energy Express centered on participation as a "fun" thing to do.

\section{Make programs fun without compromising the central focus or learning} objectives. Energy Express has shown that summer reading programs can be both fun and have an impact on reading. Energy Express has documented significant increases in children's reading achievement for eight years. While Energy Express participants didn't give reading as a reason for attending, they are well aware that reading is one of the purposes of the program. Children suggest that their friends should attend in order to improve their reading.

3. Include art in summer learning programs. Children identify art activities as what they like best about Energy Express when creative art is integrated with reading. Summer programs should regard expressive arts as an important part of the curriculum that creates enjoyment for children. 


\section{References}

Alexander, K., \& Entwisle, D. (1996). Early schooling and educational inequality:

Socioeconomic disparities in children's learning. In J.S. Coleman (Ed.), Falmer Sociology Series (pp. 63-69). London: Falmer Press.

Borman, G., Rachuba, L., Hewes, G., Boulay, M., \& Kaplan, J. (2001). Can a summer intervention program using trained volunteer teachers narrow the achievement gap? First year results from a multi-year study. ERS Spectrum, 19-30.

Cooper, H., Nye, B., Charlton, K., Lindsay, J., \& Greathouse, S. (1996). The effects of summer vacation on achievement test scores: A narrative and meta-analytic review. Review of Educational Research, 66(3), 227-268.

Cooper, H., Charlton, K., Valentine, J.C., \& Muhlenbruck, L. (2000). Making the most of summer school: A meta-analytic and narrative review. Monographs of the Society for Research in Child Development, Serial No. 260, 65(1).

Gredler, M.E. (1996). Program evaluation: data analysis and interpretation. Englewood Cliffs, N.J.: Prentice-Hall.

Lauer, P.A., Akiba, M., Wilkerson, S.B., Apthorp, H.A., Snow, D., \& Martin-Glenn, M. (2003). The effectiveness of out-of-school-time strategies in assisting low-achieving students in reading and mathematics. Aurora, CO: Mid-Continent Research for Education and Learning.

LeMenestral, S. (2002). In the Good Old Summertime: What do parents want for their kids? Unpublished manuscript.

Miltenberger, M., Phillips, R., Pruett, B., \& Triplett, S. (2002). Small groups and mentors foster relationships during summer reading program--a qualitative analysis. Journal of Higher Education Outreach and Engagement, 73$), 101-110$.

(C) Copyright of Journal of Youth Development Bridging Research and Practice. Content may not be copied or emailed to multiple sites or posted to a listserv without copyright holder's express written permission. Contact Editor at: patricia.dawson@oregonstate.edu for details. However, users may print, download or email articles for individual use.

ISSN 2325-4009 (Print); ISSN 2325-4017 (Online) 